\title{
Abdominal obesity is associated with microalbuminuria and an elevated cardiovascular risk profile in patients with hypertension
}

This article was published in the following Dove Press journal:

Vascular Health and Risk Management

9 July 2009

Number of times this article has been viewed

\section{Martin Thoenes ${ }^{1,2}$ \\ Jan-Christian Reil ${ }^{3}$ \\ Bobby Varkey Khan ${ }^{4}$ \\ Peter Bramlage' \\ Massimo Volpe ${ }^{5,6}$ \\ Wilhelm Kirch' \\ Michael Böhm ${ }^{3}$}

'Institute for Clinical Pharmacology, Medical Faculty Carl Gustav Carus,

Technical University Dresden, Germany; ${ }^{2}$ Sanofi Aventis, Global Medical Affairs, Paris, France; ${ }^{3}$ Klinik für Innere Medizin III, Kardiologie, Angiologie and Internistische Intensivmedizin, Universität des Saarlandes, Homburg, Saar, Germany; ${ }^{4}$ Department of Cardiology, Emory University School of Medicine, Atlanta, USA; ${ }^{5}$ University of Rome "Sapienza", 2nd Faculty of Medicine, S. Andrea Hospital, Rome; ${ }^{6}$ RCCS Neuromed, Pozzilli, Italy
Correspondence: Jan-Christian Reil Universitätsklinikum des Saarlandes, Klinik für Innere Medizin III, Kirrberger Straße, 66424 Homburg/Saar, Germany

Tel +49684 I I623372

Fax +49684 II623369

Email reil@med-in.uni-saarland.de
Background: Overweight and obesity are frequently associated with preventable death and have emerged as a major challenge to public health. There is an ongoing debate on the role of abdominal obesity and its value in predicting cardiovascular and renal outcomes. The present analysis evaluates the prevalence of microalbuminuria (MAU) and conventional cardiovascular risk factors in relation to measures of general and abdominal obesity.

Methods: In this multinational, observational study, 20828 hypertensive out-patients from 26 countries including Europe, North and Latin America, Middle East, and Asia were analyzed. Urinary dipstick screening for MAU was performed as well as data on patient demographics, anthropometric measures, cardiovascular risk factors, comorbid conditions, and cardiovascular drug therapy collected. MAU prevalence was determined by a stepwise logistic regression analysis with cardiovascular risk factors as univariate.

Results: In the univariate analysis, MAU prevalence systematically increased with body mass index (BMI) from $54.4 \%$ (1st tertial) to $62.1 \%$ (3rd tertial) $(\mathrm{p}<0.0001)$, an increase which was also observed for waist circumference (WC). At any level of BMI, MAU increased with WC from $53.5 \%, 54.8 \%$, and $55.0 \%$ (1st tertial of WC in all three BMI tertials) to $61.4 \%, 62.1 \%$, and $64.0 \%$ (3rd tertial of WC in all BMI tertials) $(\mathrm{p}<0.0001)$. In the multivariate analysis, WC, but not BMI was independently associated with MAU. Furthermore, overweight/obesity were associated with the presence of modifiable and nonmodifiable risk factors.

Conclusion: An abnormal WC, but not BMI appears to be independently associated with MAU, an early marker of cardiovascular and renal risk. Increasing WC confers an incremental risk for MAU at any level of BMI, underlining the prognostic importance of abdominal fat accumulation beyond general obesity.

Keywords: obesity, abdominal, microalbuminuria, cardiovascular, renal

\section{Introduction}

Obesity is frequently associated with preventable death and has emerged as a major health care challenge in the 21 st century. ${ }^{1}$ In 2004 , an estimated $32 \%$ of US adults ( $>20$ years old) were obese, $4.8 \%$ of which were morbidly obese. ${ }^{2}$ In Europe, obesity prevalence in adults differs from country to country, ranging from $10 \%-25 \%{ }^{3}$ Furthermore, a global obesity epidemic in preschool children and adolescents seems to be underway ${ }^{4}$ and highlights the urgent need for prevention. Overweight and obesity are frequently and independently associated with minor adverse health conditions, such as gallbladder or fatty liver disease, but also with serious illnesses, such as cancer. ${ }^{5,6}$ However, another major concern with obesity is cardiometabolic risk, frequently associated with atherosclerotic cardiovascular disease or diabetes. ${ }^{7}$ 
There is an ongoing discussion on the particular importance of abdominal obesity, associated with an accumulation of visceral fat tissue, as an important component of the metabolic syndrome and its associated complications. ${ }^{8-10}$ The INTERHEART Trial has identified abdominal obesity as a major independent risk factor for myocardial infarction in a large multiethnic population. ${ }^{11}$ Microalbuminuria (MAU), defined as urinary albumine excretion of $30-300 \mathrm{mg} / 24$ hours (20-200 $\mathrm{mg} / \mathrm{L}$ in the spot urine), is an established cardiovascular risk indicator in diabetes, hypertensive patients, and the general population, and has been shown to be associated with endothelial dysfunction and to be predictive for coronary artery disease, myocardial infarction, stroke, and all-cause mortality. ${ }^{12}$ Furthermore, MAU predicts the progression of diabetic nephropathy and is associated with vascular disease, congestive heart failure, diastolic dysfunction, and arterial hypertension. ${ }^{13-16}$ It was the aim of the present study, to evaluate the relationship between overweight and abdominal obesity with MAU and conventional cardiovascular risk factors in a large multiethnic hypertensive population. It was hypothesized, that abdominal obesity confers an incremental cardiovascular and renal risk which is independent of the presence of general obesity.

\section{Methods}

A large international, cross-sectional study was conducted in 2005/2006 in cardiology outpatient clinics in 26 countries worldwide as described previously. ${ }^{17}$ In brief, 21,794 patients, aged $\geq 18$ years with currently treated or newly diagnosed arterial hypertension were enrolled into the study. In all patients, urinary dipstick screening was performed (Microalbustix ${ }^{\circledR}$; Bayer HealthCare, Basel, Switzerland) and prevalence of MAU, defined as an albumin excretion of 30,80 , or $150 \mathrm{mg} / \mathrm{L}$, was determined. Furthermore, information on patient demographics, anthropometric measures, cardiovascular risk factors and co-morbid conditions as well as cardiovascular drug therapy were collected in case report form. In order to evaluate the association of overweight/obesity with the cardiovascular risk profile, patients were stratified into three tertials of body mass index (BMI) and the presence of conventional risk factors and cardiovascular drug therapy were evaluated for all three groups. The same analysis was performed in overweight patients (defined as BMI $25-30 \mathrm{~kg} / \mathrm{m}^{2}$ ) for the low versus high tertial of waist circumference (WC). All analyses were performed as univariate analysis and descriptive statistics was applied. In order to determine the association of MAU with overweight/obesity and abdominal obesity, the population was again stratified into medians and tertials (for BMI and WC) and also according to established cut-off levels for BMI $\left(<25,25-30,>30 \mathrm{~kg} / \mathrm{m}^{2}\right)$ and $\mathrm{WC}(\leq 102 \mathrm{~cm} \mathrm{vs}>102 \mathrm{~cm}$ for men, $\leq 88 \mathrm{~cm}$ vs $>88 \mathrm{~cm}$ for women) and MAU prevalence as well as odds ratios (OR) for MAU for each of these measures alone or in combination was assessed as univariate analysis. Furthermore a multivariate logistic regression analysis was performed as described previously in order to evaluate the association of BMI and WC with MAU. ${ }^{17}$ For the analyses, SAS statistical software (version 9.1.3; SAS Institute, Cary, NC, USA) was used. Continuous variables are depicted as mean values with standard deviation (SD), categorical variables as percentages with 95\% confidence intervals (95\% CI). ORs are depicted with 95\% CI. Ethics committee approval was obtained by all participating sites and informed consent forms were signed by all patients prior to study enrollment. The study was conducted according to the principles defined by the Declaration of Helsinki.

\section{Results}

\section{Characteristics of the study population}

The i-SEARCH study enrolled a total of 21,794 patients, out of which 20,868 patients were included in the present analysis. Patient-demographics, anthropometric measures, risk factor profile, comorbidities as well as cardiovascular pharmacotherapy were described elsewhere ${ }^{17}$ and are depicted in Table 1.

\section{Description of cardiovascular risk factors and pharmacotherapy}

When patients were stratified into three BMI tertials, mean WC increased with BMI from the low to the high tertial (88.7, 99.0, $110.6 \mathrm{~cm}$, respectively). The overweight group (BMI $25-30 \mathrm{~kg} / \mathrm{m}^{2}$ ) comprised a total of $43.6 \%$ of the overall population and there were more men and patients were slightly older in the high WC group $(110.0 \mathrm{~cm})$ as compared to the low WC group $(87.3 \mathrm{~cm})$. With increasing BMI, a systematic increase in the prevalence of cardiovascular risk factors/markers, such as systolic blood pressure $(147.8,148.7$, $151.1 \mathrm{~mm} \mathrm{Hg}$, respectively), history of myocardial infarction/ coronary artery disease $(24.9 \%, 28.3 \%, 30.3 \%$, respectively), physical activity $(40.0 \%, 34.7 \%, 25.8 \%$, respectively), dyslipidemia $(41.8 \%, 48.1 \%, 49.4 \%$, respectively) and type 2 diabetes $(16.1 \%, 21.5 \%, 31.2 \%$, respectively) was found. The same systematic increase in risk factors/markers was seen in the overweight group when comparing the low and 
Table I Patient characteristics

\begin{tabular}{|c|c|c|}
\hline & Parameter (mean/\%) & Total population $(n=20,868)$ \\
\hline \multirow[t]{2}{*}{ Demographics } & Male (\%) & 52.3 \\
\hline & Age (years) & 62.4 \\
\hline \multirow[t]{3}{*}{ Anthropometric measures } & BMI $\left(\mathrm{kg} / \mathrm{m}^{2}\right)$ & 28.9 \\
\hline & $W C(\mathrm{~cm})$ & 99.4 \\
\hline & WHR & 0.95 \\
\hline \multirow[t]{18}{*}{ Risk factors/markers } & $\mathrm{SBP}(\mathrm{mm} \mathrm{Hg})$ & 149.1 \\
\hline & Family history of MI/CAD (\%) & 27.8 \\
\hline & Exercise $<4$ hours/week (\%) & 65.1 \\
\hline & Exercise $>4$ hours/week (\%) & 35.0 \\
\hline & Moderate (\%) & 92.5 \\
\hline & Strenuous (\%) & 7.5 \\
\hline & Never smoked (\%) & 54.0 \\
\hline & Current smoker (\%) & 14.2 \\
\hline & No of cigarettes/day & 16.3 \\
\hline & Duration since stopped smoking (years) & 14.8 \\
\hline & Known dyslipidemia (\%) & 46.3 \\
\hline & $\mathrm{TC} \geq 5.17 \mathrm{mmol} / \mathrm{L}(\%)$ & 52.6 \\
\hline & $\mathrm{HDL}-\mathrm{C}<\mathrm{I} .16 \mathrm{mmol} / \mathrm{L}(\%)$ & 37.2 \\
\hline & $\mathrm{TG} \geq 1.69 \mathrm{mmol} / \mathrm{L}(\%)$ & 45.8 \\
\hline & Type 2 diabetes mellitus (\%) & 27.5 \\
\hline & Length of diabetes (yrs.) & 7.9 \\
\hline & $\mathrm{HbA}_{\mathrm{lc}}(\%)$ & 6.8 \\
\hline & CRP (mg/dl) & 0.9 \\
\hline \multirow[t]{10}{*}{ Comorbidities } & Heart failure (\%) & 5.8 \\
\hline & Atrial fibrillation (\%) & 8.3 \\
\hline & LVH (Sokol. > 35 mm)(\%) & 14.4 \\
\hline & CAD (\%) & 22.9 \\
\hline & History of Ml (\%) & 53.4 \\
\hline & History of myocardial revascularization (\% CAD) & 57.8 \\
\hline & Ischemic stroke (\%) & 4.8 \\
\hline & TIA (\%) & 3.8 \\
\hline & Aortic Aneurysm (\%) & 1.4 \\
\hline & PAD (\%) & 4.2 \\
\hline \multirow[t]{17}{*}{ Cardiovascular pharmacotherapy } & Thiazides (\%) & 28.3 \\
\hline & Loop diuretics (\%) & 8.7 \\
\hline & Aldosterone antagonists (\%) & 2.7 \\
\hline & CCB (\%) & 32.7 \\
\hline & BB (\%) & 43.7 \\
\hline & ACEI (\%) & 38.5 \\
\hline & ARB (\%) & 32.6 \\
\hline & $A B(\%)$ & 3.1 \\
\hline & Statins (\%) & 38.1 \\
\hline & Fibrates (\%) & 3.4 \\
\hline & ASA (\%) & 40.0 \\
\hline & Other antiplatelet drugs (\%) & 6.4 \\
\hline & Warfarin/Coumadin (\%) & 5.0 \\
\hline & Digitalis (\%) & 3.0 \\
\hline & Oral nitrates (\%) & 6.8 \\
\hline & Antiarrhythmics (\%) & 3.4 \\
\hline & $\geq$ I Diabetes drug (\%) & 19.8 \\
\hline
\end{tabular}

Abbreviations: BMI, body mass index; CAD, coronary artery disease; CRP, C-reactive protein; HbA, glycated hemogobin; HDL-C, high-density lipoprotein-cholesterol; LVH, left ventricular hypertrophy; MI, myocardial infarction; SBP, systolic blood pressure; TC, total cholesterol; TG, triglycerides; WC, waist circumference; WHR, waist-to-hip ratio. 
the high WC group. In line with the increase in cardiovascular risk, more patients received cardiovascular drug therapy with increasing BMI as well as increasing WC in the overweight group. However, in the overweight group, patients with a higher WC did not seem to receive more thiazides, calcium channel blockers (CCBs), or angiotensin receptor blockers (ARBs) (see Table 2).

\section{Prevalence of MAU in relation to $\mathrm{BMI}$}

When patients were stratified into medians and tertials of BMI and also three levels of BMI, there was a significant increase in the prevalence of MAU, with 55.6\% (95\% CI: $54.6,56.5)$ in the low versus $61.2 \%$ (95\% CI: 60.2, 62.1) in the high median $(\mathrm{p}<0.0001), 54.4 \%(95 \% \mathrm{CI}: 53.2$, $55.6)$ in the $1 \mathrm{st}, 58.6 \%(95 \% \mathrm{CI}: 57.5,59.8)$ in the 2 nd and $62.1 \%(95 \%$ CI: 60.9, 63.2) in the 3rd tertial $(\mathrm{p}<0.0001)$ and 54.4\% (95\% CI: 52.9, 55.8), 57.6\% (95\% CI: 56.6, $58.6)$ and $61.9 \%(95 \% \mathrm{CI}: 60.8,63.0)$ in patients with a BMI of $<25,25-30$, or $>30 \mathrm{~kg} / \mathrm{m}^{2}$ BMI $(\mathrm{p}<0.0001)$ (Figure 1).

\section{Prevalence of $M A U$ in relation to $\mathrm{WC}$}

When patients were stratified into medians, tertials and according to absolute levels of WC, a similar increase in MAU was detected. MAU prevalence was 54.6\% (95\% CI: $53.6,55.6)$ in the low versus $62.1 \%(95 \%$ CI: 61.1, 63.0) in the high median ( $\mathrm{p}<0.0001), 53.9 \%$ (95\% CI: 52.7, 55.1) in the 1 st, $57.4 \%$ (95\% CI: 56.2, 58.6) in the 2 nd and $63.4 \%$ (95\% CI: $62.3,64.5)$ in the 3rd tertiale ( $p<0.0001)$. In male patients with a $\mathrm{WC} \leq 102$ versus $>102 \mathrm{~cm}$, MAU prevalence was 59.0\% (95\% CI: 57.7, 60.3) and 64.7\% (95\% CI: $63.3,66.0)$, respectively ( $\mathrm{p}<0.0001)$, whereas in women, overall prevalence was markedly lower with $50.3 \%(95 \%$ CI: $48.5,52.1)$ in the group with a waistline of $\leq 88 \mathrm{~cm}$ and $56.9 \%(95 \% \mathrm{CI}: 55.7,58.1)$ in women with a waistline of $>88 \mathrm{~cm}(\mathrm{p}<0.0001)$ (Figure 2$)$.

\section{Prevalence of MAU in relation to WC at different levels of BMI}

In order to evaluate the predictive values of WC for MAU in patients at different levels of overweight/obesity, three

Table 2 Patient characteristics by BMI tertial and WC tertial (high vs low) in overweight patients (BMI $25-30 \mathrm{~kg} / \mathrm{m}^{2}$ )

\begin{tabular}{|c|c|c|c|c|c|c|}
\hline & \multirow[t]{2}{*}{ Parameter (mean/\%) } & \multicolumn{3}{|l|}{ BMI $\left(\mathbf{k g} / \mathrm{m}^{2}\right)$} & \multicolumn{2}{|l|}{ BMI $25-30 \mathrm{~kg} / \mathrm{m}^{2}$} \\
\hline & & $\begin{array}{l}\text { Ist tertial } \\
(\mathrm{N}=6948)\end{array}$ & $\begin{array}{l}\text { 2nd tertial } \\
(\mathrm{N}=6969)\end{array}$ & $\begin{array}{l}\text { 3rd tertial } \\
(\mathrm{N}=695 \mathrm{I})\end{array}$ & $\begin{array}{l}\text { WC Ist tertial } \\
(\mathbf{N}=3090)\end{array}$ & $\begin{array}{l}\text { WC 3rd terita } \\
(N=2169)\end{array}$ \\
\hline \multirow[t]{2}{*}{ Demographics } & Male (\%) & 49.9 & 57.8 & 49.0 & 35.3 & 77.3 \\
\hline & Age (years) & 63.2 & 62.7 & 61.4 & 61.6 & 64.1 \\
\hline \multirow[t]{2}{*}{ Anthropometr measures } & BMI $\left(\mathrm{kg} / \mathrm{m}^{2}\right)$ & 23.9 & 28.2 & 34.6 & 27.0 & 28.1 \\
\hline & WC $(\mathrm{cm})$ & 88.7 & 99.0 & 110.6 & 87.3 & 110.0 \\
\hline \multirow[t]{8}{*}{ Risk factors/markers } & $\mathrm{SBP}(\mathrm{mm} \mathrm{Hg})$ & 147.8 & 148.7 & 151.1 & 147.9 & 149.4 \\
\hline & Family history of MI/CAD (\%) & 24.9 & 28.3 & 30.3 & 27.2 & 29.6 \\
\hline & Exercise $>4$ hours/week (\%) & 40.0 & 34.7 & 25.8 & 36.5 & 33.9 \\
\hline & Known dyslipidemia (\%) & 41.8 & 48.1 & 49.4 & 44.6 & 48.0 \\
\hline & $\mathrm{TC} \geq 5.17 \mathrm{mmol} / \mathrm{L}(\%)$ & 50.7 & 52.3 & 55.0 & 54.4 & 51.5 \\
\hline & $\mathrm{HDL}-\mathrm{C}<\mathrm{I} .16 \mathrm{mmol} / \mathrm{L}(\%)$ & 317 & 39.0 & 40.6 & 31.6 & 44.9 \\
\hline & $\mathrm{TG} \geq 1.69 \mathrm{mmol} / \mathrm{L}(\%)$ & 38.8 & 45.5 & 52.8 & 41.4 & 50.4 \\
\hline & Type 2 diabetes mellitus (\%) & 16.1 & 21.5 & 31.2 & 16.6 & 23.2 \\
\hline \multirow{8}{*}{$\begin{array}{l}\text { Cardiovascular } \\
\text { pharmacotherapy }\end{array}$} & Thiazides (\%) & 25.9 & 27.9 & 30.9 & 27.5 & 27.0 \\
\hline & Aldosterone antagonists (\%) & 2.5 & 2.2 & 3.4 & 2.1 & 2.7 \\
\hline & CCBs (\%) & 32.2 & 31.8 & 34.0 & 31.4 & 31.4 \\
\hline & BBs (\%) & 41.8 & 43.6 & 45.6 & 43.2 & 44.8 \\
\hline & ACEs (\%) & 36.3 & 38.4 & 40.8 & 33.9 & 41.2 \\
\hline & ARBs (\%) & 30.6 & 33.2 & 34.0 & 34.6 & 32.8 \\
\hline & ABs (\%) & 2.7 & 2.8 & 3.8 & 2.5 & 3.5 \\
\hline & Statins (\%) & 34.9 & 39.1 & 40.2 & 35.4 & 40.9 \\
\hline
\end{tabular}

Abbreviations: Abs, alpha blockers; ACEs, angiotensin-converting enzyme inhibitors; ARBs, angiotensin receptor blockers; BBs, beta blockers; BMI, body mass index; CAD, coronary artery disease; CCBs, calcium channel blockers; HDL-C, high-density lipoprotein-cholesterol; MI, myocardial infarction; SBP, systolic blood pressure; TC, total cholesterol; TG, triglycerides; WC, waist circumference. 


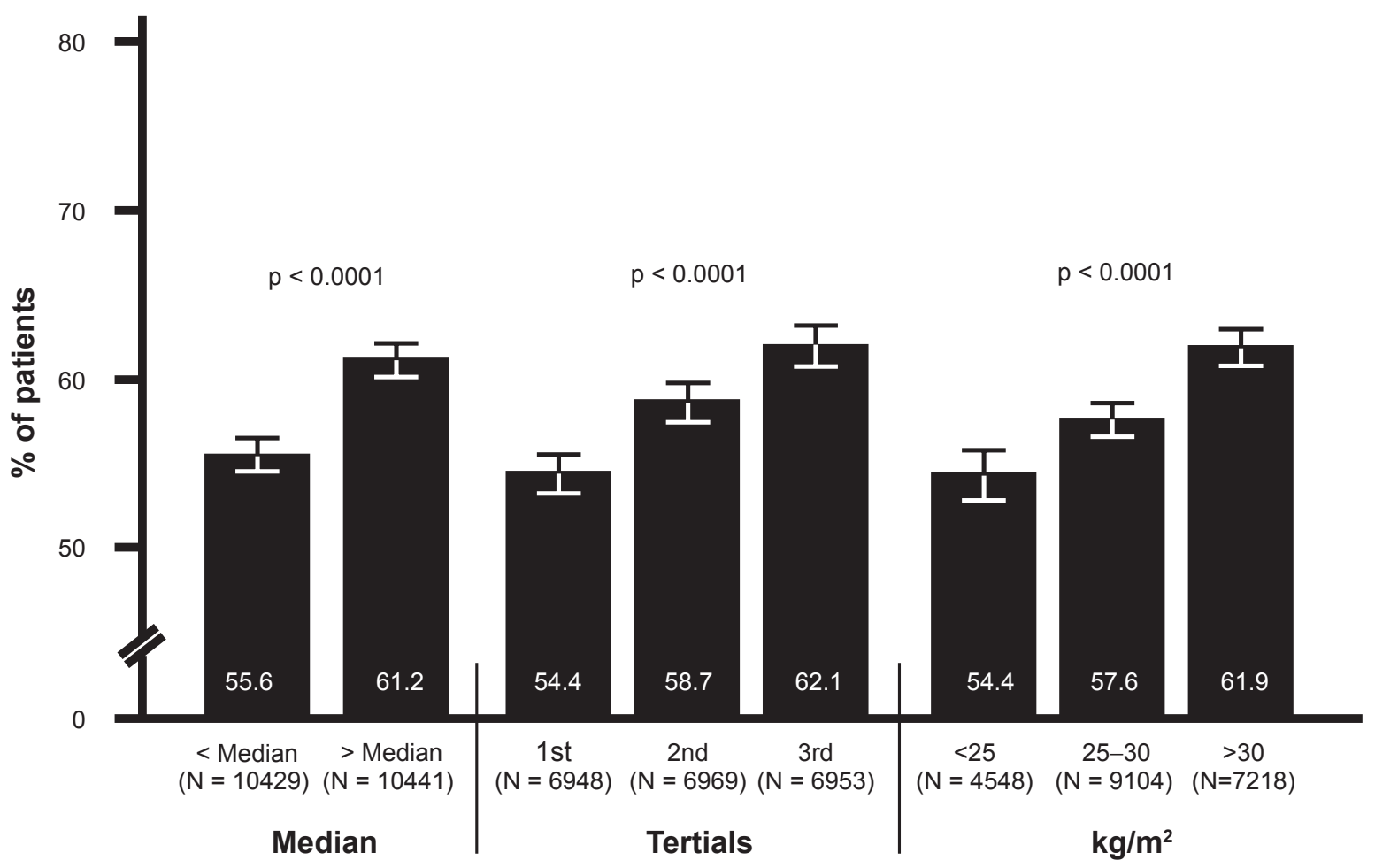

Figure I Prevalence of MAU in relation to BMI.

Abbreviations: BMI, body mass index; MAU, microalbuminuria.

tertials of WC were analyzed within each tertial of BMI. Within all three BMI groups, there was a graded increase in MAU from the low to the high WC tertial: MAU was present in $53.5 \%$ (95\% CI: $52.0,54.9)$ in the low versus $61.4 \%$ ( $95 \%$ CI: 56.6, 66.1) in the high WC tertial (1st BMI tertial, $\mathrm{p}<0.0001), 54.8 \%$ (95\% CI: 52.4, 57.2) in the low versus $62.1 \%$ (95\% CI: 60.0, 64.2) in the high WC tertial (2nd BMI tertial, $\mathrm{p}<0.0001)$ and $55.0 \%(95 \% \mathrm{CI}: 49.7,60.1)$ in the low versus $64.0 \%$ (95\% CI: $62.7,65.4)$ in the high WC tertial (3rd BMI tertial, $\mathrm{p}<0.0001$ ) (Figure 3).

\section{Odds ratio for MAU according to BMI, WC alone, or in combination}

In the univariate analysis, patients with a higher BMI had an increased risk of MAU with ORs ranging from 1.26 (95\% CI: $1.19,1.33)$ to 1.37 (95\% CI: $1.28,1.47)$ for the high versus low median or tertial, and 1.36 (95\% CI: 1.26 , 1.47) for obese patients $\left(>30 \mathrm{~kg} / \mathrm{m}^{2}\right)$ versus those at normal weight $\left(<25 \mathrm{~kg} / \mathrm{m}^{2}\right)$. Also patients with a higher $\mathrm{WC}$ are at an increased risk for MAU with an OR of 1.36 (95\% CI: $1.29,1.44)$ and $1.48(95 \%$ CI: $1.38,1.58)$ for the high versus low median or tertial. In men with a waistline $>102 \mathrm{~cm}$ versus $\leq 102 \mathrm{~cm}$, OR for MAU was 1.27 (95\% CI: 1.18, 1.38 ), a finding which was also confirmed in women, where
OR was 1.30 (95\% CI: 1.19, 1.42) for a high $(>88 \mathrm{~cm})$ versus low waistline $(\leq 88 \mathrm{~cm})$. Within each tertial of BMI, a high versus low waistline was associated with an increased risk of MAU, ranging from 1.38 (95\% CI: $1.12,1.69)$ for the 1 st , to $1.47(95 \%$ CI: 1.18, 1.82) for the 3rd BMI tertial $(\mathrm{p}<0.0001)$ (see Figure 4a). In the multivariate analysis, an abnormal versus normal WC (defined as $>102 \mathrm{~cm}$ versus $\leq 102 \mathrm{~cm}$ for men and $>88 \mathrm{~cm}$ versus $\leq 88 \mathrm{~cm}$ for women), but not BMI, was independently associated with MAU (OR 1.132, 95\% CI: 1.039, 1.233) (see Figure 4b).

\section{Discussion}

Excess in body fat mass can be measured by defining a subjects BMI (height-independent measure of weight), WC (marker of abdominal/viszeral excess fat) or waist-to-hip ratio (WHR; body shape in relation to fat deposition). An increase in BMI can indicate an increase in total body fat and has been shown not only to be linked with comorbidities such as hypertension, diabetes, coronary heart disease, but also with total mortality in men and women of different ethnic origin. ${ }^{18-20}$ Its value in predicting cardiovascular risk has been challenged by the results of the INTERHEART Study. ${ }^{11,21}$ According to this trial abdominal obesity, measured by WHR but less so by BMI, was shown to be an independent 


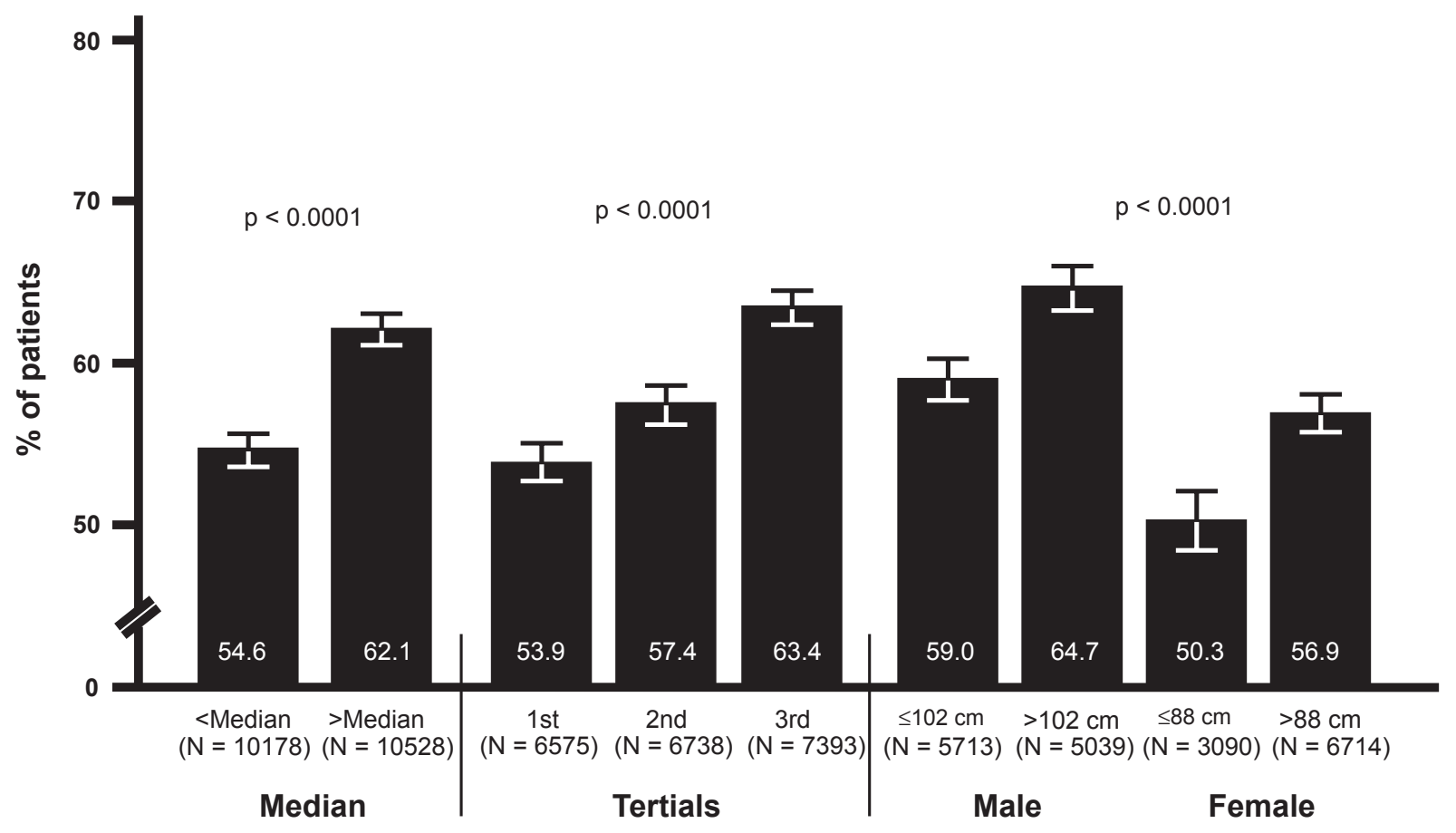

Figure 2 Prevalence of MAU in relation to WC.

Abbreviations: MAU, microalbuminuria; WC, waist circumference.

risk factor for the incidence of myocardial infarction. Our data from a large multiethnic sample of more than 20,000 hypertensive patients confirm that increases in BMI are associated with several important atherogenic risk factors, such as lack of exercise, dyslipidemia, total cholesterol, high-density lipoprotein (HDL)-cholesterol, triglycerides, and presence of diabetes. Our data also clearly confirm the elevated risk profile of abdominally obese patients, by showing a higher overall prevalence of modifiable- and nonmodifiable risk factors in patients with an excess in abdominal fat. Beside these correlations, we sought to determine the risk of cardiovascular and renal end organ damage measured by MAU, an established surrogate marker of adverse cardiovascular and renal outcomes, and its correlation with different

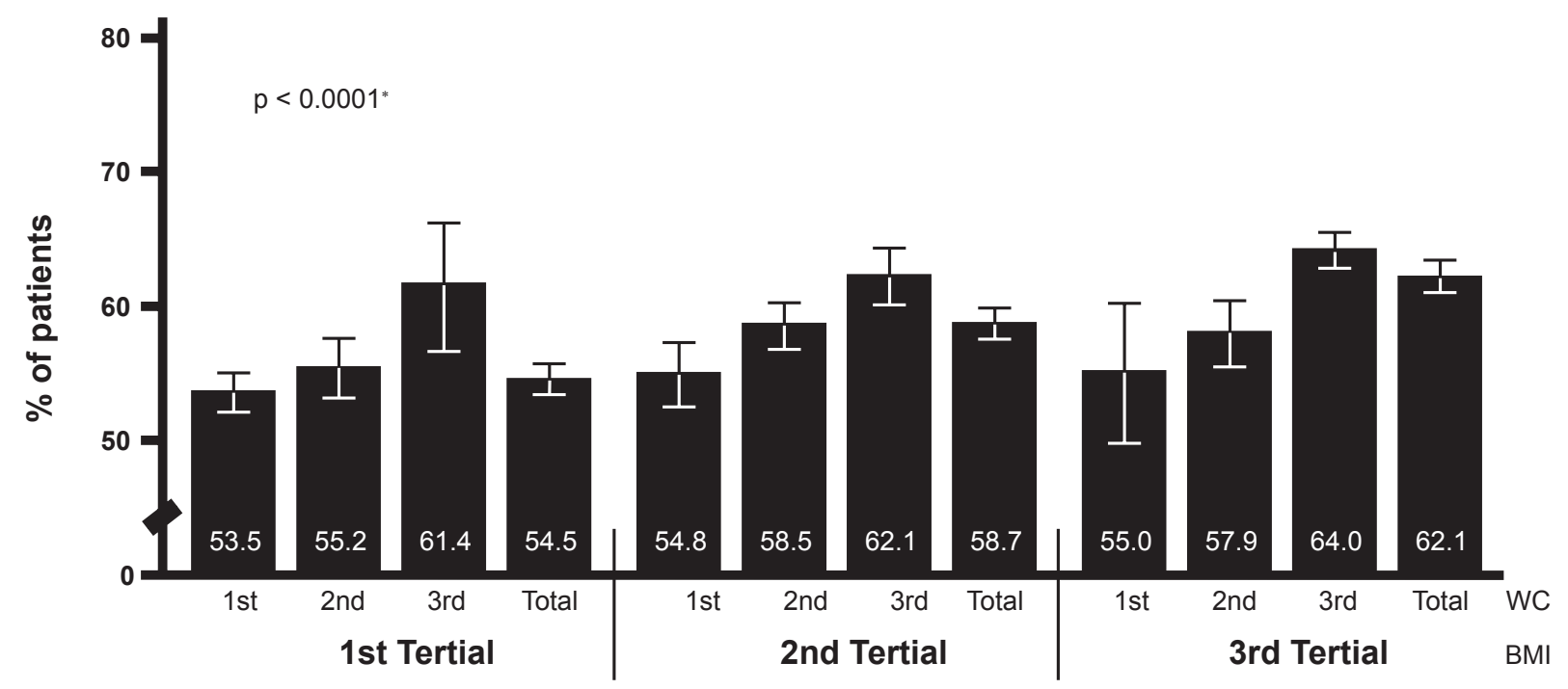

Figure 3 Prevalence of MAU in relation to BMI \&WC tertials.

Abbreviations: BMI, body mass index; $M A U$, microalbuminuria;WC, waist circumference. 


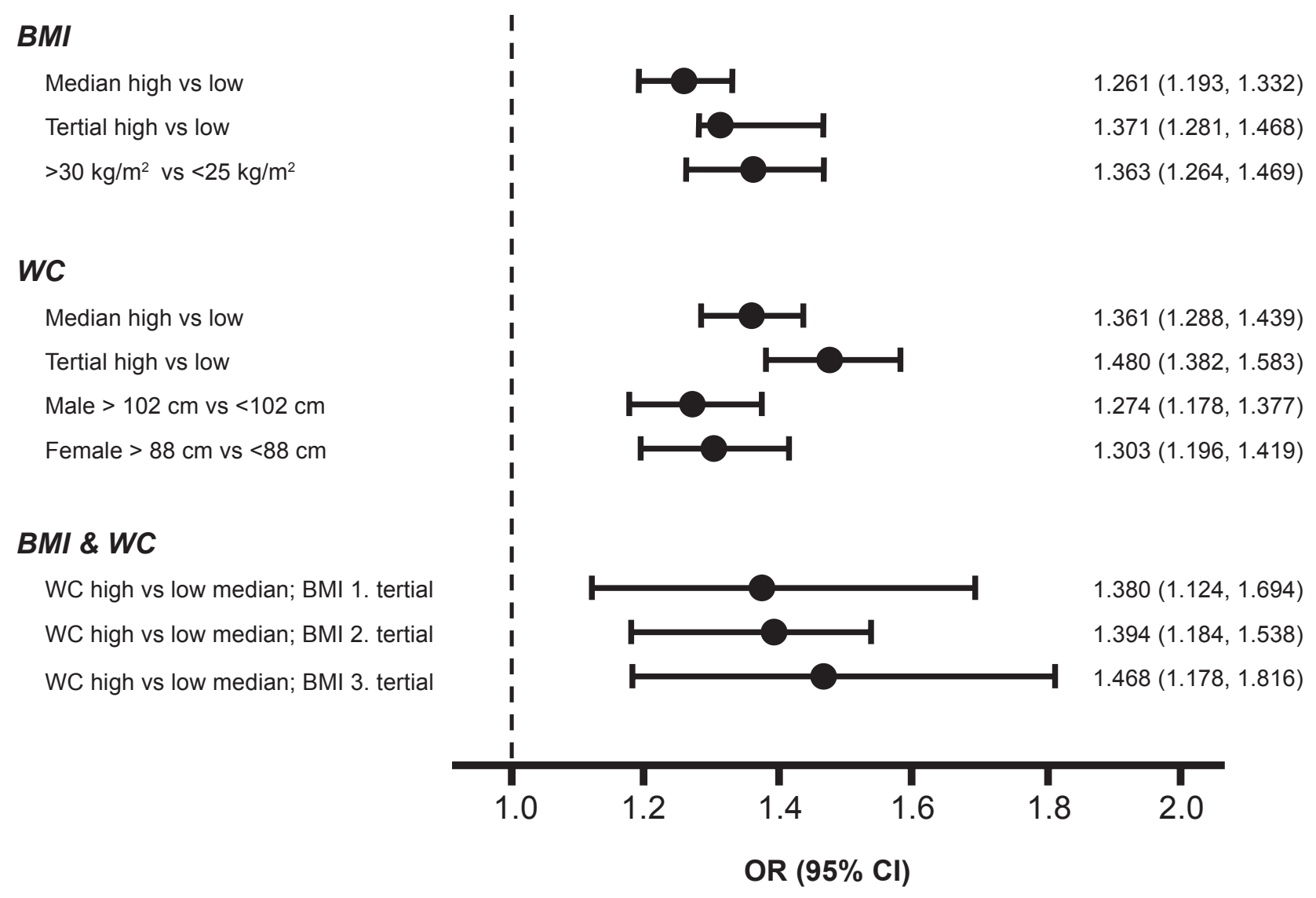

Figure 4a Odds ratio for MAU for BMI,WC and BMI \& WC (Univariate analysis).

Abbreviations: $\mathrm{BMI}$, body mass index; $\mathrm{Cl}$, confidence interval; $\mathrm{MAU}$, microalbuminuria; $\mathrm{OR}$, odds ratio; $\mathrm{WC}$, waist circumference.

measures of obesity. In three small studies, no relationship between MAU and BMI, WC, WHR, or visceral obesity, measured by computed tomography, could be detected..$^{22-24}$ In contrast, analyses from the DCCT/EDIC (Diabetes Control and Complications/Epidemiology of Diabetes Interventions and Complications) population in diabetic men and women showed that WHR, but not BMI, was associated with an abnormal urinary albumin excretion rate. ${ }^{25,26}$ In our study, a linear relationship between BMI and MAU was detected in the univariate analysis: Across all categories of BMI, MAU prevalence increased significantly with BMI by absolute $8 \%$ from the 1 st to 3 rd tertial (Figure 1). In addition, WC showed a linear relationship with the prevalence of MAU, which increased by absolute $9 \%$ from the lowest to the highest WC tertial (Figure 2). Furthermore, these data show that within each BMI tertial, a high versus low WC appears to be associated with a higher MAU prevalence, supporting the notion of abdominal obesity confering an incremental risk for early renal and cardiovascular damage at any level of BMI.

In patients with abdominal obesity, a specific constellation of cardiovascular risk factors and markers, such as elevated blood pressure, low HDL-cholesterol, hypertriglyceridemia, elevated blood glucose, and insulin levels (impaired glucose tolerance) are clustered, findings which were confirmed by our data. This population shows a doubled risk for developing cardiovascular disease or diabetes. ${ }^{8}$ Moreover, recent data from similar populations demonstrated $\mathrm{WC}$ to be superior to $\mathrm{BMI}$ in predicting cardiovascular risk in men and women. Also in a recent analysis in 24,000 patients, WC was a better predictor for an increased risk of coronary artery disease than BMI, ${ }^{27}$ results which were supported by the INTERHEART study indicating, that abdominal obesity measured by WHR represents an independent risk factor for the incidence of myocardial infarction. ${ }^{11}$ We therefore also conducted a multivariate logistic regression analysis in order to evaluate the specific relationship of WC and BMI with MAU after adjustment for various confounding variables. In our multivariate model, WC, but not BMI, was identified as an independent marker of renal and cardiovascular risk by using MAU as a surrogate marker, thereby confirming the findings from INTERHEART and Canoy and colleagues ${ }^{11,27}$ in this large sample of hypertensive patients. 


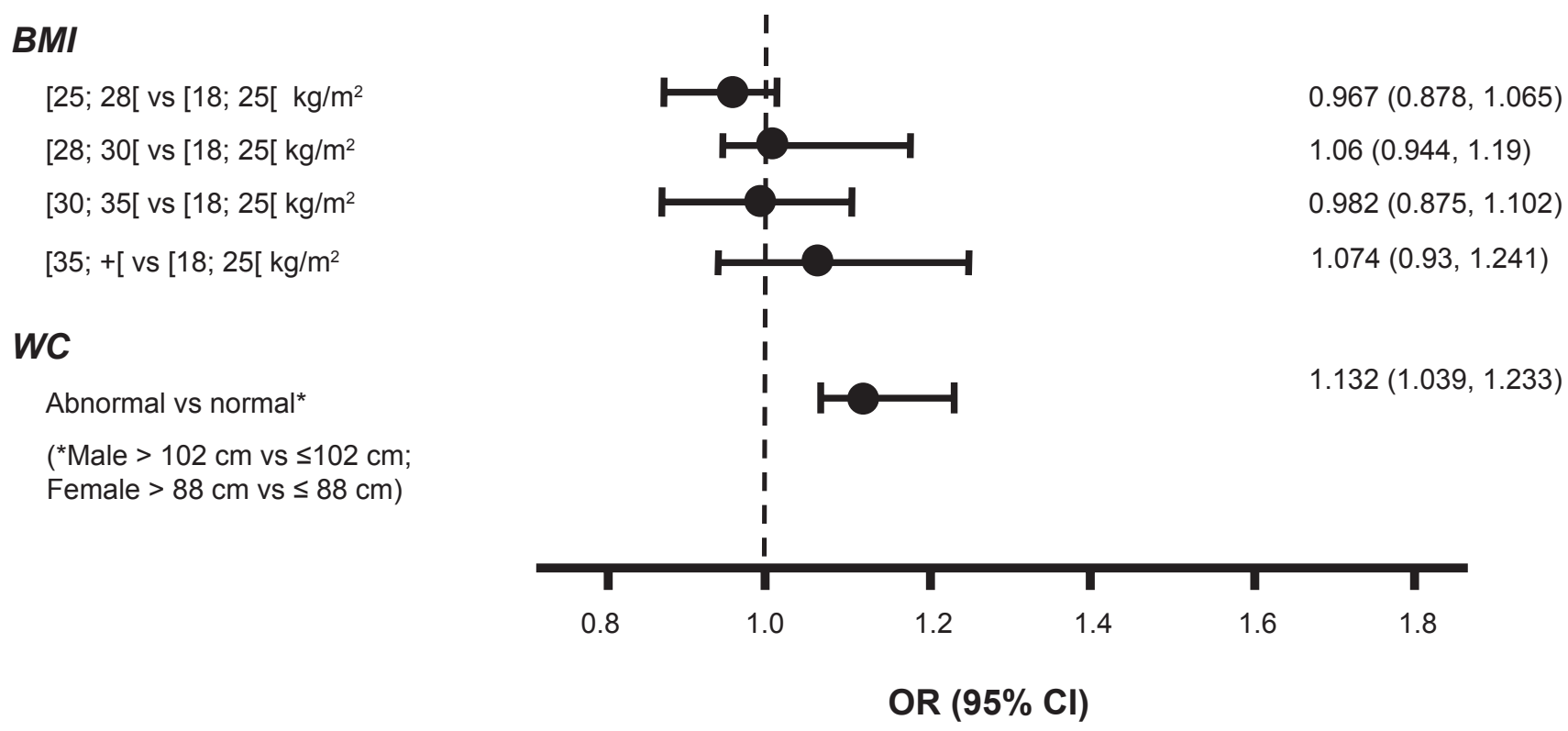

Figure 4b Odds ratio for MAU for BMI \&WC (Multivariate analysis).

Abbreviations: $\mathrm{BMI}$, body mass index; $\mathrm{Cl}$, confidence interval; $\mathrm{MAU}$, microalbuminuria; $\mathrm{OR}$, odds ratio; WC, waist circumference.

At present, the specific pathophysiological link between obesity and MAU can only be speculated. Abdominal obesity represents a key component of the metabolic syndrome. The crucial components that may link abdominal obesity to other features of the metabolic syndrome and end-organ damage are presumably elevated insulin levels, peripheral tissue resistance to the insulin-sensitizing action of leptin, and increased macrophage infiltration in fat tissues with concomitant release of proinflammatory cytokines. ${ }^{28,29}$ The described metabolic changes favor intracellular lipid deposition in adipose tissue, hepatocytes, skeletal and cardiac myocytes as well as in endothelial cells. ${ }^{30,31}$ Intracellular fat deposits, associated with inflammatary cytokines and ischemia (pro-thrombotic state), frequently associated with abdominal obesity, might decrease the functional integrity of the endothelial wall and lead to MAU.

Taken together, the data presented from this large international cohort of hypertensive patients confirms the presence of an increased cardiovascular risk profile in patients with overweight and specifically abdominal obesity. Futhermore, a linear relationship of different measures of overweight/obesity with MAU, an established marker of cardiovascular disease and renal damage, was detected. However, only abdominal obesity, as measured by WC was independently associated with a higher prevalence of MAU. The data supports the current perception of the pathophysiological role of an excess in viszeral fat and underlines the importance of weight loss-efforts as essential goal in cardiovascular risk management and possibly also the prevention of renal damage.

\section{Limitations}

At present, it can only be speculated whether the observed relationship between overweight/obesity and MAU is similar across all ethnic groups included into the present analysis. However, since the study population was dominated by patients from western countries (about 15,500 patients), the conclusions mostly apply to Caucasian populations. For this reason, the present analysis also evaluated MAU in relation to specific cut-off levels of BMI and WC, recommended by international guidelines for this population. The main analysis was performed by a single dipstick screening test for MAU, where international guidelines recommend, that MAU should be established by three separate tests out of which two measurements should be positive. However, dipstick testing at one single occasion has been established as a usefull screening tool in epidemiological research.

\section{Acknowledgments}

JCR and MT contributed equally. The i-SEARCH program was supported by sanofi-aventis. MB, MV, MT, and PB received support from sanofi-aventis. MB and JCR are supported by the Deutsche Forschungsgemeinschaft (Klinische Forschergruppe KFO 196). 


\section{References}

1. Adams KF, Schatzkin A, Harris TB, et al. Overweight, obesity and mortality in a large prospective chohort of persons 50 to 71 years old. N Engl J Med. 2006;355:763-778.

2. Ogden CL, Carroll MD, Curtin L, McDowell MA, Tabak CJ, Flegal KM. Prevalence of overweight and obesity in the United States, 1999-2004. JAMA. 2006;295:1549-1555.

3. World Health Organisation. Obesity: preventing and managing the global epidemic. Report of a WHO consultation. World Health Organ Tech Rep Ser. 2000;894:i-xii, 1-253.

4. Wang Y, Lobstein T. Worldwide trends in childhood overweight and obesity. Int J Pediatr Obes. 2006;1:11-25.

5. Must A, Spadano J, Coakley EH, Field AE, Colditz G, Dietz WH. The disease burden associated with overweight and obesity. JAMA 1999;282:1523-1529.

6. Calle EE, Thun MJ. Obesity and cancer. Oncogene. 2004;23: 6365-6378.

7. Scaglione R, Argano C, Di Chiara T, Licata G. Obesity and cardiovascular risk: the new public health problem of worldwide proportions. Expert Rev Cardiovasc Ther. 2004;2:203-212.

8. Despres JP, Lemieux I. Abdominal obesity and metabolic syndrome. Nature. 2006; $444: 881-887$.

9. Menke A, Muntner P, Wildman RP, Reynolds K, He J. Measures of adiposity and cardiovascular disease risk factors. Obesity. 2007;15:785-795.

10. Freiberg MS, Pencina MJ, D’Agostino RB, Lanier K, Wilson PW, Vasan RS. BMI vs waist circumference for identifying vascular risk Obesity. 2008;16:463-469.

11. Yusuf S, Hawken S, Öunpuu S, et al; on behalf of the INTERHEART Study investigators. Effect of potentially modifiable risk factors associated with myocardial infarction in 52 countries (the INTERHEART study): case-control study. The Lancet. 2004;364:937-951.

12. Thoenes M, Bramlage P, Khan BV, Schieffer B, Kirch W, Weir MR. Albuminuria: pathophysiology, epidemiology and clinical relevance of an emerging marker for cardiovascular disease. Future Cardiol. 2007;3:519-524.

13. Parving HH, Lehnert H, Bröchner-Mortensen J, Gomis R, Andersen S, Arner P; Irbesartan in Patients with Type 2 Diabetes and Microalbuminuria Study Group. The effect of irbesartan on the development of diabetic nephropathy in patients with type 2 diabetes. $N$ Engl J Med. 2001;345(12):870-878.

14. Jensen JS, Feldt-Rasmussen B, Strandgaard S, Schroll M, Borch-Johnsen $\mathrm{K}$. Arterial hypertension, microalbuminuria, and risk of ischemic heart disease. Hypertension. 2000;35(4):898-903.

15. Vaur L, Gueret P, Lievre M, Chabaud S, Passa P; DIABHYCAR Study Group (type 2 DIABetes, Hypertension, CARdiovascular Events and Ramipril) study. Development of congestive heart failure in type 2 diabetic patients with microalbuminuria or proteinuria: observations from the DIABHYCAR (type 2 DIABetes, Hypertension, CArdiovascular Events and Ramipril) study. Diabetes Care. 2003;26(3):855-860.

16. Mimran A, Ribstein J, Du Cailar G. Angiotensin II receptor antagonists and hypertension. Curr Opin Nephrol Hypertens. 1999;8(39):359-363.
17. Böhm M, Thoenes M, Danchin N, Bramlage P, La Puerta P, Volpe M Association of cardiovascular risk factors with miroalbuminuria in hypertensive individuals: the i-SEARCH global study. $J$ Hypertens. 2007;25:2317-2324.

18. Laaksonen DE, Lakka HM, Niskanen LK, Kaplan GA, Salonen JT, Lakka TA. Metabolic syndrome and development of diabetes mellitus: Application and validation of recently suggested definitionsof the metabolic syndrome in a prospective cohort study. Am J Epidemiol. 2002;156:1070-1077.

19. Lakka HM, Laaksonen DE, Lakka TA, Niskanen LK, Kumpusalo E, Tuomilehto J, Salonen JT. The metabolic syndromeand total and cardiovascular disease mortality in middle-aged men. JAMA. 2002;288:2709-2716

20. Ninomiya JK, L'Italien G, Criqui MH, Whyte JL, Gamst A, Chen RS. Association of the metabolic syndrome with history of myocardial infarction and stroke in the Third National Health and Nutrition Examination Survey. Circulation. 2004;109:42-46.

21. Anand SS, Islam S, Rosengren A, Franzosi MG, Steyn K, Yusufali AH, Keltai M, Diaz R, Rangarajan S, Yusuf S; on behalf of the INTERHEART Investigators. Risk factors for myocardial infarction in women and men: insights from the INTERHEART study. Eur Heart $J$. 2008;29(79):932-940

22. Nielsen S, Jensen MD. Relationship between urinary albumin excretion, body compostion and hyperinsulinemia in normotensive glucosetolerant adults. Diabetes Care. 1999;22:1728-1733.

23. Hoffmann IS, Jimenez E, Cubeddu LX. Urinary albumin excretion in lean, overweight and obese glucose tolerant indiduals: its relationship with dyslipidemia, hyperinsulinemia and blood pressure. J Hum Hypertens. 2001;15:407-412.

24. Yesim TE, Ugurlu S, Caglar E, Balci H, Ucgul A, Sarkis C, Acbay O, Gundogdu S. Investigation of microalbuminuria in non-diabetic, normotensive obese women. Intern Med. 2007;46:1963-1965.

25. Sibley SD, Thomas W, de Boer I, Brunzell JD, Steffes MW. Gender and elevated albumin excretion in the Diabetes Control and Complications Trial/Epidemiology of Diabetes Interventions and Complications (DCCT/EDIC) cohort: role of central obesity. Am J Kidney Dis. 2006; 47:223-232.

26. De Boer ICH, Sibley SD, Kestenbaum B, et al; Diabetes Control and Complications Trial/Epidemiology of of Diabetes Interventions and Complications Study Research Group. Central obesity, incident microalbuminuria, and change in creatinine clearance in the epidemiology of diabetes interventions and complications study. J Am Soc Nephrol. 2007; 18:235-243.

27. Canoy D, Boekholdt M, Wareham N, et al. Body fat distribution and risk of coronary heart disease in men and women in the european prospective investigation into cancer and nutrition in norfolk cohort. A populationbased prospective study. Circulation. 2007;116:2933-2943.

28. McGarry JD. Banting lecture 2001: Dysregulation of fatty acidmetabolism in the etiology of type 2 diabetes. Diabetes. 2002;51:7-18.

29. Bagby SP. Obesity-initiated metabolic syndrome and the kidney: a receipe for chronic kidney disease? J Am Soc Nephrol. 2004;15:2775-2791.

30. Schaffer JE. Lipotoxicity: When tissues overeat. Curr Opin Lipidol. 2003;14:281-287.

31. Unger RH, Orci L. Lipoapoptosis: Its mechanism and its diseases. Biochim Biophys Acta. 2002;1585:202-212.
Vascular Health and Risk Management

\section{Publish your work in this journal}

Vascular Health and Risk Management is an international, peerreviewed journal of therapeutics and risk management, focusing on concise rapid reporting of clinical studies on the processes involved in the maintenance of vascular health; the monitoring, prevention and treatment of vascular disease and its sequelae; and the involvement of

\section{Dovepress}

metabolic disorders, particularly diabetes. This journal is indexed on PubMed Central and MedLine. The manuscript management system is completely online and includes a very quick and fair peer-review system, which is all easy to use. Visit http://www.dovepress.com/ testimonials.php to read real quotes from published authors. 